\title{
Dois Servos da Natureza: A pintura de Francisco Brennand e Aloisio Magalhães vista por um escritor
}

É talvez de estranhar, neste "mundo de clarezas definidas", em que as artes, antes reunidas sob o signo comum da poesia, parecem definitivamente separadas, que um escritor, deixando de lado o campo em que procura se especializar, se atreva a pesquisar noutro que lhe é estranho, para estudar a obra de dois pintores. Mas, a obedecermos às tendências que dominam atualmente no campo das artes, dentro de pouco tempo teremos uma situação em que somente os pintores falarão de pintura, somente os poetas estarão autorizados a falar de poesia, e em que as artes estarão para sempre enclausuradas numa pureza estéril, talvez mortal para elas.

De modo que é uma tendência natural de defesa procurar e amar outras artes que não a sua, pois quero declarar, logo de início, que absolutamente não concordo com aquele modo de entender, e que, se bem que esteja convencido de que cada arte tem seu objeto natural, há uma enorme liberdade de escolha dentro de seus meios e uma maior ainda possibilidade de amor e troca entre elas.

A obra dos dois pintores que vamos analisar é, aliás, um exemplo típico do que aqui se afirma, da liberdade de escolha dos meios, e o fato de que o convívio entre as artes, em geral, é proveitoso para cada uma delas, em particular, explica meu interesse pela pintura dos dois jovens mestres pernambucanos. É impossível negar o proveito que decorreu para a obra de alguns escritores, entre os quais se poderia citar Stendhal e Proust, de seu amor pela pintura. É como se esses mestres, no limiar de suas obras, prestes a dizer adeus ao mundo das coisas para se envolverem a fundo no das paixões humanas, povoado de sombra e como que votado à condenação, quisessem ainda manter uma ligação com o outro, o da natureza menor, através de seus irmãos que nele permanecem e por intermédio de quem pudessem guardar sua primitiva fidelidade às coisas da natureza - águas, frutos, árvores, coisas e animais.

Justifica-se, assim, que um escritor fale de pintura, ainda que corra o risco de ser considerado herético pelos próprios pintores de quem fala, e mais ainda quando se trata de alguém que tem, desde muitos anos, guardado fielmente seu amor por essa arte sutil e gloriosa, e quando o assunto sobre que se detém é a obra de dois artistas de sua geração, obra cuja importância se acentua dia a dia e que o toca profundamente, tanto por suas 
qualidades excepcionais, como por nele encontrar uma ressonância especial, uma profunda identidade de anseios e aspirações a qual, tendo começado desde seus mais verdes anos de artista, só se tem firmado com o tempo.

Aqui é o caso de se perguntar se essa voz, assim interessada, não será parcial. Creio porém que o caso não é de se julgar a obra desses dois pintores: seria antes uma tentativa de compreensão e de esclarecimento. Se a obra de um artista só pode ser julgada pelo tempo - o que já me parece discutível - isso não implica em que seus contemporâneos não possam e devam ter dela uma opinião ou manifestar sua emoção diante daquilo que ela representa.

Acresce que uma coisa posso afiançar: falando da obra de Aloisio Magalhães e de Francisco Brennand, asseguro que encaro o trabalho desses dois pintores com a mesma severidade e com o mesmo amor que sempre empreguei na crítica do meu, de tal modo sinto-me identificado com eles. Posso, desse modo, manter uma certa imparcialidade que, à falta de outro motivo, seria resultado de uma dedicação fiel e desinteressada, de uma observação de mais de dez anos, de uma convivência quase diária e que só me tem sido proveitosa.

Como já se deve ter observado pelos trabalhos expostos ${ }^{57}$, cada um desses dois pintores tem seus próprios meios de expressão, afastando-se bastante um do outro, sob certos aspectos. Sentimos que cada um deles tem suas qualidades originais, suas tendências diferentes, seu mundo à parte, como não podia deixar de suceder, tratando-se de dois artistas autênticos. Sentimos sobretudo que Aloisio Magalhães se inclina mais para a pintura de paisagem, na qual predomina uma visão como que distanciada, panorâmica da natureza, enquanto que Francisco Brennand procura antes uma visão íntima e aproximada do objeto, tendo ainda uma acentuada preferência pela figura humana.

Para empregar uma fórmula meramente didática - um tanto esquemática e rígida, como toda fórmula, mas que tem o mérito de simplificar as coisas para um melhor entendimento - diria que cada um deles segue uma das duas tendências que se podem delinear na pintura contemporânea, após a chamada ruptura que o fim do século passado e o começo do atual causaram nesse domínio. Após essa ruptura, colocaram-se de um lado os pintores chamados abstratos e os de tendência abstrata; do outro, os figurativos.

Esses nomes facilitam o entendimento e o agrupamento de inclinações e acredito que, somente por isso, se justificam. Mas causam também muita confusão às pessoas desprevenidas, de modo que é preciso alertar essas pessoas sobre eles.

57 Esta conferência de Ariano Suassuna foi proferida durante a abertura de uma exposição dos dois pintores analisados, realizada na sede da Associação de Cultura Franco-Brasileira, então situada à Rua Dom Bosco, $\mathrm{n}^{\circ} 1367$, no Recife (Nota dos editores). 
Gostaria de apresentar o problema, antes de me deter sobre a pintura de nossos dois artistas, propriamente, a fim de definir certas posições e certas palavras que terei de empregar aqui.

Em princípio, pode-se ligar a primeira tendência - a corrente dos pintores abstratos e de tendência abstrata - à pintura medieval e à primitiva, e a segunda - a dos figurativos - à Renascença.

Como exemplo dessa pintura figurativa da Renascença, à qual se ligam em maior ou menor grau, direta ou indiretamente, todos os pintores de figuras, eu apresentaria um quadro que me é muito caro, “Tarquínio e Lucrécia”, de Ticiano. Talvez se encontrassem outros mais típicos e até mais valiosos, mas este quadro, além de sugestões de toda espécie e de suas qualidades plásticas intrínsecas, planteia o da redução dos elementos pictóricos, que apaixona todos os pintores contemporâneos. Para não complicar muito a exposição, direi que os elementos tradicionais de um quadro são a linha, a cor, o volume e a luz, devendo ainda se encarar no quadro, dada a sua importância na estrutura, a composição, isto é, a maneira de dispor esses elementos em relação entre si.

Os quadros renascentistas, em sua maioria quase absoluta, apresentam esses elementos perfeitamente dissociados, segundo se pode ver no quadro de Ticiano ou na "Leda", da escola de Leonardo, por exemplo.

Se acentuo esse fato é porque ele me parece de excepcional importância, para a compreensão da pintura figurativa, que, de modo geral, acompanha nesse ponto os renascentistas, assim como para a da abstrata, que dela se afasta, reduzindo os elementos tradicionais.

Na verdade, quem quer que venha a se deter na contemplação de um quadro da Renascença, virá a ter essa ideia de harmonia e de volutuosidade, conseguida através de belos corpos sabiamente iluminados, em que uma suave luz de ouro, egressa de não sei que crepúsculo, banha corpos jovens docemente reclinados na sombra. Uma pintura cheia de sugestões e de nuances de toda espécie, sugestões que seriam hoje talvez recusadas como estranhas à pintura. É Leda com seu olhar enigmático e sorridente, povoado de malícia e de matizes, voltando os olhos para um lado a fim de escondê-los da vista do cisne que acaba de possuí-la e de ocultar o mistério de sua intimidade a quem a tocara tão de perto. É Tarquínio abatendo-se sobre essa forma arredondada e dourada, como a própria imagem da vida cálida e fugitiva que ele quisesse captar, emergindo ambos da sombra, como se tivessem sido não pintados mas evocados pelos toques seguros desse pincel que a mão de um velho sorridente manejava, cheio de compreensão e amor diante das paixões humanas que ele conhecia e perdoava, de amor e compreensão pela carne das mulheres e dos jovens, a que dava igual tratamento, apenas sugerindo a separação 
através dos toques mais acobreados com que tratava esta, como se quisesse assim, apesar de todo o seu amor pelas mulheres, declarar alto e a bom som seu culto pelo objeto, seu amor pela natureza, mais comovente ainda para nós quando nos lembramos de que ele ia morrer em breve, de que tinha perfeita consciência desse fato e queria, ainda assim, cantar uma última vez a vida e a juventude.

Ouçamos o renascentista por excelência, Leonardo, falando a respeito de sua arte:

"Que é corpo sombreado, que é a sombra primitiva, que é a sombra derivada e que é a luz? É treva, luz, cor, figura, ubicação, distância, proximidade, movimento, repouso, coisas todas que o espírito pode compreender sem necessidade de nenhum processo manual. Tudo isto forma a ciência da pintura que penetra no espírito dos contempladores... Em pintura deve-se fazer as figuras de tal maneira que o contemplador possa conhecer facilmente, por seus gestos e ademanes, o conceito de sua alma. Se você tem que fazer um bom homem falando, faça com que seus gestos sejam aqueles que acompanham as boas palavras. As mulheres devem ser representadas com atitudes de sensitiva, com as pernas juntas, os braços reunidos, a cabeça um pouco baixa e inclinada para um lado. $\mathrm{O}$ supremo prazer dos pintores consiste em repetir os mesmos motivos, os mesmos rostos, maneiras e roupagens, numa história idêntica, assim como em fazer a maior parte dos rostos à semelhança do de seu autor. Muitas vezes isto me encheu de admiração, porque não conheci um só que em todas as suas figuras não parecesse ter posado pessoalmente para elas".

Se atentarmos para alguns desses conceitos, teremos uma ideia das diferenças que separam nosso tempo da Renascença. "O espírito pode compreender", "o conceito de sua alma”, "as mulheres com atitudes de sensitiva, com as pernas juntas, os braços reunidos" etc. Através dessas palavras entramos em contato com uma pintura intelectual e conceptiva, riquíssima em sugestões que hoje seriam consideradas estranhas à pintura, uma pintura que procurava a verdade na harmonia, através do amoroso estudo da vida e da natureza em todas as suas formas, com um verdadeiro culto pela figura humana, como se pressentisse que ela era, de entre todas as obras da criação, a mais apta a sugerir, a significar, aquela que oferece a maior possibilidade de ritmo, de harmonização dos contrastes, de conflito e de amor. Uma pintura em que os elementos tradicionais se encontram, perfeitamente dissociados e recebendo igual tratamento, para que o pintor pudesse se servir do maior número de meios a seu alcance, tendo, como tinha, muito a sugerir e a glorificar.

Quanto à pintura da outra tendência, deve-se chamar a atenção para dois fatos, que se referem também a esses elementos: em primeiro lugar, há predominância de um deles, a cor, sobre todos os demais. A linha e a composição são arbitrárias, subordinadas tão somente ao gosto do pintor. Assinala-se ainda uma tendência para achatar a pintura, 
em detrimento do relevo, a fim de dilatar as superfícies e possibilitar a sua exploração através da cor. Esta absorve a luz, que se confunde com ela, numa valorização igual dos planos. Tudo isso tem como resultado a abstração, em maior ou menor grau, de acordo com a arte de cada um.

É interessante verificar como, do mesmo modo que a pintura renascentista já continha em si esses elementos absolutamente diferenciados, a medieval e a primitiva já se encaminhavam para a abstração. E deve-se também dizer que a arte de nosso tempo é antes ligada a essa pintura de tendência abstrata do que é figurativa. Mas é conveniente lembrar também que em qualquer tempo encontraremos pintores amados pelas duas correntes. Um Piero della Francesca, um Cézanne, um Vermeer de Delft, que conseguem uma abstração talvez inigualada pelos que a procuram, fazendo-o através da figura, hão de se constituir sempre numa advertência contra as fórmulas e contra os que a elas se apegam, em separações e conflitos estéreis que a nada levam. Porque, sejam quais forem as diferenças de temperamento, de escolha de meios, de elementos predominantes, de achados puramente plásticos ou sugestivos, todos os pintores (com exceção dos abstracionistas sectários e acadêmicos) têm um terreno comum em que chegam forçosamente a se encontrar: o amor pelo objeto, na natureza, e o amor pela matéria, no quadro.

É aí que os pintores se entenderão, sejam quais forem suas inclinações, e há de ser sempre uma honra para o nosso tempo ter efetuado aquela ruptura sem deixar de reconhecer a legitimidade das tendências mais diversas, permitindo um campo largo em que cada criador pode exercer à vontade a sua liberdade, para enriquecimento da pintura e florescimento das vocações mais diversas.

Ouvimos o que disse Leonardo sobre a pintura, como suas preferências eram pela pintura de sugestões, pelo amor da figura, pelo estudo dos mestres, pela observação, pela pintura como deleitação da vista e do espírito, na sua qualidade de arte tão intelectual como qualquer outra. Ouçamos porém o que diz ele sobre a forma:

"O espírito do pintor deve ser semelhante ao espelho que se transforma sem cessar, de acordo com a cor das coisas que reflete e que se enche de tantas imagens quantos são os objetos que estão perto dele. Sabendo disto, você não poderá se considerar bom pintor se não for mestre universal, capaz de imitar com sua arte todas as qualidades das formas que a natureza produz. Não deixarei de dizer, entre meus preceitos, uma nova invenção de teoria, ainda que pareça mesquinha e quase ridícula, porque ela é muito apropriada e muito útil para predispor o espírito às mais variadas invenções. Eis aqui de que se trata: se você olhar certos muros manchados e feitos com pedras misturadas, supondo que tenha que fazer alguma obra, poderá ver ali, sobre esse muro, os simulacros de países diversos, com suas montanhas, seus rios, suas rochas, suas árvores, suas planícies, os grandes vales, as colinas e muitos diversos aspectos. Poderá ver nele batalhas e vivos 
movimentos de figuras, rostos estranhos, vestiduras e mil coisas mais [até aqui trata-se da pintura figurativa], que poderá reduzir a formas precisas e úteis" [e esta é a parte em que Leonardo se revela também formalista, admitindo claramente a redução das formas naturais a outras formas precisas e úteis na pintura].

Creio que não existe pintor, figurativo ou abstrato, que não subscreva essas palavras, pois qualquer um deles, desde que seja um artista autêntico e não se deixe prender por controvérsias, há de ser humilde diante da natureza, seja na procura de formas novas e variadas, seja como sugestão estética, anterior ao quadro, na sua qualidade de fornecedora de cores, de linhas, de composições sempre novas, enfim, como um material selvagem e rico, de onde o artista deverá partir, na sua obra de escolha e de criação. A natureza, no mínimo, fornecerá essa matéria, que o pintor poderá e deverá "reduzir" às formas úteis e precisas de que fala Leonardo.

É essa unidade final que vamos encontrar na obra de Francisco Brennand e na de Aloisio Magalhães, esse ponto comum em que as duas se encontram, sejam quais forem as diferenças de temperamento dos pintores e diferente a orientação que cada um dá à sua pintura, ambas tão valiosas no que se refere à revelação da natureza de nossa região.

Se me é permitida uma notação de caráter particular, assinalaria como ponto de partida da análise que tentamos fazer da pintura desses dois grandes artistas a visão de um trecho de paisagem nos arredores do Recife. Creio que qualquer um de nós, pelo menos uma vez, já se deixou encantar com um desses recantos que a nossa cidade e a região que a cerca nos proporcionam num dia de verão, em que a luz do céu é absolutamente azul e transparente, o céu incomparável do Recife e de Olinda, puro e brilhante como um sinal da eternidade; se me é permitida essa evocação pessoal, fugindo um pouco ao tom que de ordinário se exige numa conferência como esta, evocaria essa lembrança pessoal como ponto de partida deste estudo, uma lembrança em que se deveria fazer especial referência a uma água azul turquesa, refletindo um céu de lápis-lazuli, uma água mais escura do que o céu, rasa, imóvel, pura, como se tivesse sido recortada na pedra que lhe dava a cor, especialmente para a terra avermelhada sobre que repousava, céu e água puros e imóveis, sendo que o céu tranquilo e distante, e a água avistada por entre a folhagem de esmeralda dos cajueiros, que o sol fazia cantar em sua refulgência, folhas duras e geométricas, mas com uma limitação que os raios vivificavam, a um tempo rígidas e vibrantes, sob o sol do começo do crepúsculo. A tarde fora violenta, mas a obliquidade atual do sol já deixava o leito vermelho da estrada na sombra, se bem que um pouco acima dele dançasse uma luz dourada e suave. Alguns animais - cabras e ovelhas - pastavam ao lado e então as rodas do carro ergueram uma nuvem de pó de cobre e de ouro, a que logo o sol começou a transfigurar, móvel, solene, e, no entanto, comovedor e plácido, um canto sóbrio, capaz de evocar as iluminações mediterrâneas e que, ao mesmo tempo que enriquecia a luz do sol, dançante sobre a estrada, era por ela enriquecido, num comércio 
misterioso e sagrado como aquele que deve ter acontecido entre Danae e sua chuva de ouro. Uma luz que tudo sugeria e que tudo parecia consentir e tornar possível, com a só exigência da beleza, mas que tivesse sido posta, com seus tranquilos animais, com sua relva de ouro, com todo o seu convite à volutuosidade e ao prazer, diante do esmalte da água e da folhagem, para ser corrigida e equilibrada, num apelo à harmonia, como que a exortar-nos e advertir-nos de que a sensualidade, as doces formas reclinadas, a suave luz do crepúsculo e os sentimentos que lhe são próximos, levam a um esquecimento e a uma indolência que é preciso pelo menos temperar sabiamente, numa tentativa de equilíbrio que é uma herança e um exemplo que os antigos nos deixaram.

É assim que, se me fosse permitido ligar estas palavras a um sentimento tão pessoal, tomaria a visão dessa paisagem como ponto de partida da análise da obra de Francisco Brennand e de Aloisio Magalhães. É como se este fosse fiel àquele primeiro aspecto da paisagem entrevista e a outros que lhe são próximos, e aquele ao segundo, por suas ligações tradicionais e por sua arte povoada de sugestões, se bem que, de acordo com a advertência que fiz de início, não haja separação efetiva entre as duas.

Seguindo esse roteiro, que, a exemplo do que acontece com os pintores, me foi fornecido pela natureza, gostaria de mostrar a pintura de Aloisio Magalhães ligada às formas mais exatas da paisagem. Uma pintura cheia de harmonia e de pureza, em que a natureza aparece como que sintetizada e purificada, sob uma visão por assim dizer aérea da paisagem, ora mais patente, ora mais reduzida às formas precisas de que fala Leonardo, formas que dão a impressão de terem brotado espontaneamente, de uma visão anterior ao quadro. E é talvez muito sugestivo o fato de que, quando o pintor achou o caminho que ora percorre, deu a todos os que o acompanhavam de perto a impressão de ter achado um tesouro por acaso, tamanha era a diferença entre a primeira fase, em que caminhava tateando, e a pintura surgida de repente, perfeita e sóbria, como obra da idade madura. Mas estaria enganado quem assim pensasse, porque enquanto desempenha suas funções cotidianas, enquanto se diverte, ama ou sofre, mesmo enquanto dorme, o trabalho subterrâneo do artista continua, invisível mas incessante e, no caso particular de que trato, Aloisio Magalhães trabalhava em silêncio, impregnava-se da vida e das formas de nossa paisagem, estudava e observava. Viveu assim mais de um ano, creio, depois de sua volta da Europa, que constitui um marco em sua pintura. Um dia, enfim, tinha realizado sua síntese e estava pronto a começar. E foi o que estamos vendo, essa pintura acabada e serena.

É uma qualidade essencial a nosso tempo - e será sempre sua honra, como já disse - esse largo horizonte que se oferece à liberdade, com uma capacidade de aceitação mais ampla do que as épocas precedentes se atreveram pelo menos a sonhar. Essa conquista, no entanto, não se fez sem sacrifícios. No que se refere à pintura, por exemplo, desapareceram quase inteiramente a emulação e a imitação, não havendo mais lugar para a gran- 
de escola, em que a oficina de cada pintor era uma academia, um lugar de aprendizado, em que os novos recebiam a herança que os antigos lhes transmitiam e passavam a dar sua contribuição pessoal à grande corrente que a tradição oferecera.

Isto não quer dizer que a pintura contemporânea não tenha características comuns. Desde o começo que se tentou esboçar aqui algumas de suas linhas mestras mais ou menos comuns, através da valorização da cor, da tendência à abstração - ambas conseguidas pela exploração da superfície e pelo achatamento dos relevos - das ligações com a pintura medieval e com a primitiva e da composição arbitrária, entregue aos achados individuais. E graças a esse predomínio do arbitrário e do individual, pode-se dizer que hoje em dia cada pintor refaz sozinho o caminho da pintura, como se fosse único, legando uma contribuição que ele próprio moldou e que se extingue praticamente com seu criador.

Por outro lado, se se perdeu quase inteiramente a possibilidade de imitação e de emulação tradicionais, é preciso salientar o caráter de grandeza e de coragem que existe nesse terrível isolamento: se o artista, como foi o caso de Aloisio Magalhães, consegue sobreviver à falta de apoio tradicional e acha seu próprio meio de expressão, tem como prêmio uma originalidade talvez desconhecida em outros tempos. E se o número de pintores atuantes é proporcionalmente menor, se mais dura é a escolha, maior é a riqueza plástica, maior a liberdade para os poucos e, com isso, mais fecundo do que nunca o solo pictórico. Essa é talvez a causa de não haver em nosso tempo uma pintura média, capaz de sustentar a arte de uma geração em que não houvesse mestres: a pintura contemporânea, ou viverá da obra dos mestres, ou perecerá. E a prova disso é o deserto que povoa a Europa, após o florescimento extraordinário da Escola de Paris, cujos mestres, Rouault, Matisse, Braque, Picasso, Derain, Léger, estão desaparecendo pouco a pouco sem ninguém que os substitua ou com imitadores sem originalidade e portanto mortos.

É dentro dessa orientação corajosa e deliberadamente escolhida que Aloisio Magalhães caminha afim de expressar aquilo que eu chamaria a sua verdade. Essa verdade ele a procura, em primeiro lugar, através de suas características universais, daquilo que o aproxima da arte de seu tempo. A cor e a luz confundidos, tanto porque essa valorização da cor corresponde a um anseio inato do artista, como por causa da qualidade de nossa luz, a qual, por sua violência, ilumina os objetos de um modo quase uniforme, atenuando as sombras e achatando naturalmente os volumes. Quem quer que olhe um quadro seu, há de notar essa qualidade rara da cor, distribuída em superfícies às vezes dilatadas até a abstração. A composição pessoal, sugerida ao artista pela natureza que o cerca, os telhados, a água, as palmeiras, os trechos de rua de súbito encontrados ou reencontrados e só agora descobertos pelo olhar do pintor, cada vez mais arguto e preciso. O amor da natureza domada. Não servil: antes colaboradora do artista, num intercâmbio fecundo e sem conflitos. $\mathrm{O}$ amor ao equilíbrio e à harmonia, traço fundamental de sua personali- 
dade, servindo a essa troca com a natureza em que vemos, por exemplo, o artista dando tratamento verdadeiro e adequado a nossos telhados característicos, os quais retribuem esse tratamento oferecendo ao pintor zonas delimitadas e amplas em que pudesse exercer à vontade seu gosto pela cor e procurar se aproximar assim de seu mundo interior. Ou a disposição dos conjuntos comuns à cidade e a seus arredores, fornecendo, com seus motivos, oportunidade para que ele desenvolvesse essa concepção puramente pessoal da composição que faz, ela também, parte desse mundo e que aparece com toda a sua pujança em alguns dos desenhos, seguros e conscientes. Ou ainda a pureza do céu e das águas recebendo seu equivalente pictórico nos quadros, quase todos com água, palmeiras, árvores, céu e telhados, vibrantes, eternos e imóveis, por estarem assim na natureza. E pode-se dizer que o pintor realizou tamanha identificação com a paisagem, que nós amamos sua pintura por reconhecer nela a natureza de nossa região, capital amada do Nordeste inteiro. Mas é ela tão rica em achados pessoais, sendo, como é, uma tentativa de revelação do mundo inteiro do artista, que hoje, ao encontrarmos certos trechos do Recife, passamos a amar o que antes nos passava despercebido e que somente o pintor soube achar. Então acontece o contrário: em vez de descobrirmos nossa paisagem em sua pintura, passamos a descobrir quadros seus na paisagem. Porque quanto mais apura seus meios, mais o artista se aproxima de sua verdade e se ele escolhera para pintar exatamente esses aglomerados de telhados, de águas e de palmeiras, fora já porque eles se assemelhavam aos elementos dessa sua verdade interior e profunda. Eram e são elementos de nossa natureza, mas são também a imagem mais aproximada desse seu tesouro particular que, como todo artista, possui e que passa a vida inteira tentando revelar.

É muito difícil precisar e prever nesse domínio, mas creio não estar equivocado quando afirmo que, no caso particular de Aloisio Magalhães, essa verdade se reveste de uma busca da pureza, uma procura da verdade através da maior sobriedade de meios possível, uma verdade a que ele serve e servirá na sua intimidade e no mais profundo de seus anseios profissionais, a que, como todo artista, dedicará o melhor de si mesmo, gastando toda a sua vida no esforço nobre e contínuo de libertá-la de suas impurezas, para apresentá-la, clara e gloriosa, na sua simplicidade final, com sua face sorridente e pura, caráter interior do artista e inteireza autêntica de sua obra. E se pudesse destacar um quadro, para apontá-lo à contemplação e a uma atenção especial, destacaria a "Paisagem Azul", juntamente com a outra que lhe é tão próxima, realizada com elementos iguais, se bem que com uma luz diferente, a "Paisagem Amarela", quadros que exemplificam tudo o que quis dizer sobre a arte de Aloisio Magalhães. Patentearia as relações da pintura que esses dois quadros resumem tão bem, com aquela água azul turquesa, entrevista por entre uma folhagem de esmeralda, ambas dispostas de um modo que se poderia chamar "imperativo e brilhante", pura, sóbria, eterna e sem outra qualidade que não fosse seu valor plástico intrínseco, como se ambos, artista e paisagem, quisessem nos advertir de que o mundo exterior às coisas e íntimo dos homens é irrevogavelmente condenado à impureza. E assinalaria ainda como o artista, partindo da natureza que nos cerca, vai pouco a 
pouco incorporando-a à sua arte, caminhando em busca de sua verdade, que é uma verdade sóbria e pura, através dos caminhos de seu tempo, uma arte em que permanecem os elementos da natureza, sintetizados, purificados e por isso mesmo livres. "Procuro narrar com verdade e clareza o que se passa no meu coração. Só vejo uma regra: ser claro. Se não sou claro todo o meu mundo se aniquila", disse o grande Stendhal. Essas palavras, juntamente com as sentenças que escolheu para figurarem junto a seus quadros, esclarecem muita coisa sobre a obra de Aloisio Magalhães, cujo mundo também se aniquilará se ele não for claro e verdadeiro, uma obra que muitos considerarão difícil exatamente por causa de sua simplicidade, harmonia e clareza, num mundo em que essas qualidades se tornam cada vez mais raras. Mas quem quer que tenha amor pela pintura, isto é, quem quer que considere a pintura uma coisa essencial, não deixará de reconhecer nos trabalhos aqui expostos, em primeiro lugar, a originalidade de seus meios, a inteireza da obra, a fidelidade à paisagem por meio de uma visão pessoal dela, a riqueza da cor, a síntese extraordinária realizada entre uma concepção pessoal da composição e os elementos de nossa natureza. E depois, sobretudo nos últimos trabalhos, uma interiorização cada vez mais profunda, que, tendo seu ponto de partida nos achados plásticos que nossa natureza forneceu ao artista, se encaminha no sentido de um despojamento, de uma economia de meios, de uma limpidez e sobriedade que só podem ser fruto de sua aguda consciência pictórica e de um corajoso amor por aquilo que constitui sua verdade.

Fidelidade a seu pensamento, harmonia e equilíbrio, pureza de meios, procura incessante de tudo isso através da simplicidade e do despojamento: eis o nobre escopo da pintura de Aloisio Magalhães e acredito que ele está certo. Não porque ache que a pintura obedeça a esses cânones ou a quaisquer outros, mas porque essa é uma sua inclinação natural, não procurada, e porque vejo o resultado de seu trabalho. Em arte a única verdade é a beleza e a clara simplicidade é uma das mais valiosas pedras de toque dessa beleza e dessa verdade, aqui confundidas numa unidade comovente e perfeita.

Já a pintura de Francisco Brennand seria ligada às formas entrevistas posteriormente e sugeridas pelos contrastes de luz, pela poeira dourada, pelos tranquilos animais que pastavam, pois tudo isso faz parte do mundo desse outro grande artista, desse seu mundo interior ao mesmo tempo semelhante e oposto ao de Aloisio Magalhães, como não podia deixar de ser e que procurarei sugerir, antes do que delimitar.

Para a compreensão de sua pintura, seria conveniente, antes de qualquer outra coisa, procurar desfazer uma confusão que reina a respeito de um problema em torno do qual se dividem os artistas e que já foi sugerido anteriormente quando se afirmou que a pintura de Aloisio Magalhães era, de modo geral, ligada à arte de seu tempo.

Esse problema é o da obrigação, ou da suposta obrigação, que tem o artista de se colocar em consonância com as aspirações, com o gosto de seus contemporâneos, na 
qualidade de orientador, que deve participar dos problemas de sua época, de sua região e de seus semelhantes.

Em primeiro lugar, parece-me contestável esse papel de orientadora e de educadora que procuram dar às artes; e, depois, creio que é um problema mais ou menos insolúvel o de descobrir os grupos e indivíduos realmente credenciados para determinar o que é que interessa ao tempo, o que é autenticamente do tempo ou oposto a ele. Lembro-me bem do caso de Proust, a quem se aconselhava que fizesse arte popular, "sacrificando os refinamentos da forma, bons para ociosos" e a quem ele respondia com muita propriedade que "tinha frequentado muito a gente mundana para saber que eram eles os verdadeiros analfabetos, e não os operários eletricistas, e que a este respeito, uma arte, popular pela forma, seria antes destinada aos membros do Jockey do que aos da confederação geral do trabalho".

Acredito, com ele, que haja muita confusão de planos a esse respeito. O artista terá esses problemas e neles se imiscuirá ou não, de acordo com seu temperamento e suas inclinações. Acredito mesmo que, como cidadão, ele pode e deve dar sua contribuição a seu tempo. Quanto à arte é que não tem ele nenhuma obrigação dessa espécie. Enquanto está na rua ou em casa, fora de sua oficina, o artista é um homem igual aos outros; mas diante de sua tela, como um eletricista diante de sua máquina, sua obrigação é seu ofício, isto é, no seu caso particular, a realização de uma obra bela e a fidelidade a esse mundo interior que é o seu. Se é fiel e - o que é mais essencial - se a beleza é conseguida, ninguém tem o direito de perturbá-lo com reivindicações de outra natureza. Vou mais longe em declarar que acredito que quanto menos preocupações estranhas à sua arte tiver o artista, mais oportunidade terá ele de realizar sua obra autêntica.

Em suma, acredito que o pintor não deve alistar seu quadro a serviço seja da igreja, seja do partido, seja da classe, seja disso que os mundanos consideram o povo e em nome de quem elaboram uma estética popular, que, afinal, não passa de uma subestimação das fontes autenticamente populares. Deve o artista antes alistar-se ele próprio a serviço do quadro, dentro da maior liberdade, com os meios que preferir e tendo como único escopo atingir a beleza, o que fará revelando aos outros, menos dotados, a visão desse mundo interior, rico e novo que é o seu. Somente assim pode e deve ele servir a seu semelhante, enriquecendo sua visão do mundo, tarefa que só pode parecer sem importância àqueles que não precisam de arte nenhuma, seja a aristocrática, seja a pretensa arte popular.

A colocação desse problema é útil para a compreensão da obra de Francisco Brennand, não porque ele se coloque deliberadamente em oposição a seu tempo, mas porque na realização dessa obra e seguindo uma inclinação natural, ele não toma conhecimento do problema de "ser de seu tempo". O pintor nunca se deixou perturbar por ele, e do 
mesmo modo que veremos sua arte se desenvolver pelo estudo de nossa natureza - o que, em última análise, atende a algumas das exigências dos ortodoxos da arte contemporânea ou da arte alistada - vê-la-emos absorta no estudo da cerâmica persa, dos mestres da Renascença, de Vermeer, de Cézanne, enfim de tudo aquilo que lhe pode ser útil e que é, por isso mesmo, legítimo.

Se não fosse esta uma palavra que se presta a tantos equívocos, diria que o mundo que Francisco Brennand procura revelar, servindo-se dessa amplitude de meios que é uma qualidade inata sua, é um mundo aristocrático. Um mundo de formas nobres e repousadas, em que a volutuosidade desponta, sugerida e discreta, como um elemento de exaltação à vida. Francisco Brennand é uma prova da afirmação de Leonardo de que os pintores se comprazem em repetir sempre os mesmos motivos e a esboçar sempre o próprio rosto, tomando rosto aqui no sentido de seu retrato total, seja no sentido físico, seja no sentido espiritual. Pois o que ele procura exprimir, como todo artista, é esse mundo que constitui sua única propriedade e que é o único dotado de autenticidade para ele.

Já alguns anos atrás escrevia-me o pintor algumas palavras, nas quais fixava os elementos através dos quais sonhava revelar esse mundo: "Em mim, acima de tudo, distingo o amor pela natureza. Um sentimento, por assim dizer, religioso da vida. Uma espécie de surpresa, continuamente renovada, diante do mais insignificante detalhe deste mundo. Um verdadeiro amor pelos animais e pelos frutos, essa gente de vida silenciosa. A felicidade em toda a sua plenitude. É isso o que sonho para minha pintura e para minha vida", dizia ele, agora já comentando um quadro de Courbet, um pintor a quem o artista muito admira, e uma exposição de naturezas mortas do século XVII até nossos dias, que vira em Paris. E continuava: "O mármore desses bois, a relva úmida e densa, onde repousam os homens e esse céu incomparável, sem tempestades e bem distante da terra. A campina imensa e sem fim. O repouso, a quietude, a paciência e o amor. Trazer a pintura para suas origens. Reencontrar o objeto na plenitude de sua forma”.

Se atentarmos para essas palavras, para os quadros expostos, assim como para o trecho que o pintor escolheu especialmente para figurar junto destes, veremos que ele tem se mantido fiel àquele programa, se se pode chamar programa uma aspiração tão espontânea de sua natureza.

Partindo dele, veríamos o artista, na sua fase de Paris, entregue às cores quentes e sóbrias e ao estudo da composição, para empregá-las em interiores e naturezas mortas de gosto quase flamengo, se bem que os cálidos ocres italianos repontassem aqui e ali. Depois, levado insensivelmente pelos objetos e frutos mais humildes e simples de nossa natureza, na sua fase de São Francisco, vê-lo-íamos chegar àquela cor delicada e pura de esmalte que têm os frutos, pintados com um amor comovente, em naturezas mortas de composição perfeita. Acompanharíamos um estudo constante e acurado da figura hu- 
mana, nos desenhos de corpos femininos, mulheres que o pintor revela inesperadamente com olhos sorrateiros e oblíquos, mas com uma obliquidade diferente da de Leonardo, o qual parecia compreendê-las e sorrir-lhes amavelmente, enquanto que o nosso jovem mestre parece julgá-las e julgá-las sem indulgência. E veríamos as faianças, em que todo o seu conhecimento da figura e do desenho ressalta, exatamente porque os meios que ele emprega nelas, e que se opõem à orientação dada geralmente à faiança pelos pintores de seu tempo, têm que viver, esses seus meios, da pureza da linha, da composição e da vida pura e sem mancha de nosso azul e branco tradicionais.

Teríamos assim uma visão das características gerais de sua pintura: o estudo e o amor da natureza, da obra dos mestres e da composição tradicional. Uma apego quase pagão aos elementos naturais, aos corpos, aos frutos, essa procura da felicidade pelo prazer dos sentidos, pela contemplação das formas naturais, pelas sugestões de toda espécie, sempre expressas por meio de uma extraordinária riqueza plástica. Encontraríamos naturezas mortas em que a cor, ressaltando dos matizes de sombra, é exaltada ao máximo, até atingir uma espécie de luz de esmalte, com os frutos transfigurados amorosamente até que se conseguisse uma cálida carnação, que chega a evocar os corpos clássicos. A figura fixada em faianças de gosto fino, sóbrio e tradicional, em que a pureza do desenho está à altura de nosso azul e branco, aristocrático e harmonioso. Uma segurança de desenho que é aí mais valorizada pelo isolamento, despojado que está das cores e de outras sugestões que têm para mim a mesma legitimidade, mas que o artista considerará talvez menos puras.

E eu gostaria de salientar o domínio cada vez maior exercido pelo artista sobre seus meios, sobre uma violência natural, sobre a cor, sobre a figura, a composição, as coisas de nossa tradição mediterrânea e nordestina, a luz, tudo isso aportando num quadro que, do mesmo modo que o anterior de Aloisio Magalhães, aponto como uma obra-prima à contemplação. Assinalaria neste quadro todas as qualidades a que me referi: a delicada sensualidade, a exaltação à vida, o tratamento seguro dado às figuras, o desenho verdadeiro, pessoal e firme, a luz cálida de nosso verão, tendo como resultado a quase identificação de luz e cor que já assinalávamos na pintura de Aloisio Magalhães; a fidelidade à natureza: o mar esmeraldino e transparente, a folhagem, o amor pagão pelas formas e elementos da natureza, aqui mais exaltado como se o pintor fosse mesmo um adorador do sol e expusesse a ele seus sonhos para que o deus os exalçasse; as ligações tradicionais, remotas, mas nem por isso menos presentes, evocando dois jovens deuses mediterrâneos sob a luz tropical e num mar tropical, evocação sugerida pela bela cabeça de mulher, que parece na verdade intemporal, jovem, vigorosa, sóbria e harmoniosa; a pureza da cor, a verdade conseguida através de formas pessoais, tudo isso realizando uma unidade absoluta, marca da verdade e da beleza.

E chegamos à conclusão, já sugerida de início, de que, sejam quais forem as ten- 
dências e os temperamentos dos dois pintores - na verdade, pelo menos em seu estado atual, a pintura de um é inatual e inclinada à tradição, e a do outro, mais ligada à pintura contemporânea - ambos vêm a se encontrar nesse terreno que lhes é comum - $o$ amor pelo objeto e pela cor e às formas - porque ambos são servos da natureza. E somos gratos a esses dois artistas que, numa imitação da criação divina, fazem presentes no mundo elementos de beleza que não existiriam sem eles e sem esse desejo ardente que os possui de revelar esse mundo interior, fixando em formas eternas e domadas as formas fugidias e selvagens da vida, tarefa que é ao mesmo tempo seu senhor e servo e sua obsessão de cada instante. Porque com esse trabalho incessante, com esse combate contínuo contra o inexistente, vão ele povoando o mundo, revelando a nós mesmos nossa natureza, possibilitando enfim novos elementos ao rito sagrado e antigo desse culto a que se pode chamar o claro mistério da beleza. 